\title{
Reconstitution of the membrane protein OmpF into biomimetic block copolymer-phospholipid hybrid membranes
}

\author{
Matthias Bieligmeyer ${ }^{1, \S}$, Franjo Artukovic ${ }^{2}$, Stephan Nussberger ${ }^{*}$, Thomas Hirth $^{1,3}$, \\ Thomas Schiestel $^{3}$ and Michaela Müller ${ }^{*} 3$
}

Open Access

\author{
Full Research Paper \\ Address: \\ ${ }^{1}$ Institute of Interfacial Process Engineering and Plasma Technology, \\ Department of Chemical Interfacial Process Engineering, University of \\ Stuttgart, Nobelstraße 12, 70569 Stuttgart, Germany, ${ }^{2}$ Institute of \\ Biomaterials and Biomolecular Systems, Department of Biophysics, \\ University of Stuttgart, Pfaffenwaldring 57, 70550 Stuttgart, Germany \\ and ${ }^{3}$ Fraunhofer Institute for Interfacial Engineering and \\ Biotechnology, Department of Interfacial Engineering and Materials \\ Science, Nobelstraße 12, 70569 Stuttgart, Germany

\section{Email:} \\ Stephan Nussberger* - Nussberger@bio.uni-stuttgart.de; \\ Michaela Müller ${ }^{*}$ - Michaela.Mueller@igb.fraunhofer.de \\ * Corresponding author \\ § Current address: Aesculap AG, Am Aesculap-Platz, 78532 \\ Tuttlingen, Germany \\ Keywords: \\ biomimetics; block copolymer; lipopolymer mixture; OmpF \\ reconstitution; self-assembly
}

\author{
Beilstein J. Nanotechnol. 2016, 7, 881-892. \\ doi:10.3762/bjnano.7.80
}

Received: 21 December 2015

Accepted: 18 May 2016

Published: 21 June 2016

This article is part of the Thematic Series "Functional nanostructures biofunctional nanostructures and surfaces".

Guest Editor: C. Wege

(c) 2016 Bieligmeyer et al.; licensee Beilstein-Institut. License and terms: see end of document.

\begin{abstract}
Structure and function of many transmembrane proteins are affected by their environment. In this respect, reconstitution of a membrane protein into a biomimetic polymer membrane can alter its function. To overcome this problem we used membranes formed by poly(1,4-isoprene-block-ethylene oxide) block copolymers blended with 1,2-diphytanoyl-sn-glycero-3-phosphocholine. By reconstituting the outer membrane protein OmpF from Escherichia coli into these membranes, we demonstrate functionality of this protein in biomimetic lipopolymer membranes, independent of the molecular weight of the block copolymers. At low voltages, the channel conductance of $\mathrm{OmpF}$ in $1 \mathrm{M} \mathrm{KCl}$ was around $2.3 \mathrm{nS}$. In line with these experiments, integration of OmpF was also revealed by impedance spectroscopy. Our results indicate that blending synthetic polymer membranes with phospholipids allows for the reconstitution of transmembrane proteins under preservation of protein function, independent of the membrane thickness.
\end{abstract}

\section{Introduction}

Protein pores facilitate the transfer of molecules across lipid membranes with high fidelity and selectivity. In the field of biotechnology, they are particularly attractive for single-mole- cule DNA sequencing [1-5] and stochastic sensing of ions and macromolecules [6-10]. The well-defined dimensions of the protein pores furthermore offer a high potential in technical ap- 
plications, for example the desalination of water using aquaporins or the controlled release of antibiotics from OmpF-functionalized nanoreactors [11-15].

Although the chemical and physical properties of natural phospholipid bilayers are optimized for the functional reconstitution of integral proteins, these membranes are often not applicable in technical processes due to their high fluidity and lack of longterm stability $[16,17]$. Therefore, novel approaches substitute phospholipids by amphiphilic block polymers that form membranes with a mechanical strength up to 10 times larger than that of phospholipid bilayers [18-24]. Vesicles formed by synthetic block polymers (polymersomes) can be modified in a similar way as vesicles made from phospholipids (liposomes) [25-28]. Although polymer membranes are generally thicker than those made of lipids, the successful integration of membrane proteins has been shown [24,29-32]. However, their function and dynamics could be impaired due to the unnatural environment within the polymer membranes [33-37]. Bacterial OmpF channels, for example, did not show typical closing behavior when reconstituted into poly(2-methyl-2-oxazolineblock-dimethylsiloxan-block-2-methyl-2-oxazoline) triblock copolymer membranes [38].

More recently, it has been proposed to 'tune' the properties of polymeric membranes by blending them with phospholipids to bring together the mechanical stability and the inherent biofunctionality of polymeric and lipidic membranes, respectively $[39,40]$. Until now, most studies focused on the conditions influencing the appearance of lipopolymer assemblies, such as temperature or composition details [41-44]. Also the influence of additives, e.g., detergents, oligosaccharides or enzymes on polymer-lipid miscibility and membrane stability has been analyzed [45]. Although the insertion and distribution of OmpF and the potassium channel MloK1 in lipopolymer films has been studied, the functionality of both proteins in a lipopolymer environment has not been assessed yet $[46,47]$.

In the present work, we studied the reconstitution of OmpF from Escherichia coli into biomimetic lipopolymer membranes, generated by self-assembly of amphiphilic poly(1,4-isopreneblock-ethylene oxide) block copolymers (PIPEO) and 1,2diphytanoyl-sn-glycero-3-phosphocholine (DPhPC). To vary the membrane thickness, PIPEO with three different molecular weights were chosen from a library of various PIPEO, which we had synthesized in an attempt to design new amphiphilic molecules that self-assemble in aqueous solutions into membranes (unpublished results).

PIPEO was used because it possesses a low glass-transition temperature and thus high chain flexibility mandatory for pro- tein incorporation [31]. In contrast to the mostly used hydrophobic poly(dimethylsiloxane) blocks, the structure of the hydrophobic poly(isoprene) blocks of PIPEO resembles more closely that of unsaturated hydrophobic lipid tails [30]. Moreover, PIPEO can potentially be cross-linked within the hydrophobic block to further increase membrane stability.

OmpF was chosen as transmembrane protein, because it remains stable not only in harsh detergents but also at high temperatures [48-50]. In order to retain the polymeric character of the membranes, the amount of lipid used was limited to $10 \mathrm{~mol} \%$. Eventually, membranes were analyzed using confocal laser scanning microscopy, voltage clamp measurements and impedance spectroscopy.

\section{Results and Discussion Block copolymer synthesis}

Poly(1,4-isoprene-block-ethylene oxide) block copolymers (PIPEO) were designed at poly(isoprene) (PI) to poly(ethylene oxide) (PEO) ratios that are known to foster the formation of polymeric bilayers in aqueous solutions $[19,20,51]$. The three copolymers PIPEO $_{877}$ (1), PIPEO $_{1530}$ (2) and PIPEO $_{3188}$ (3) were synthesized with molecular weights between $877 \mathrm{~g} \mathrm{~mol}^{-1}$ and $3188 \mathrm{~g} \mathrm{~mol}^{-1}$ to allow for a compromise between membrane fluidity, stability and thickness (Figure 1A) [18,21]. The molecular properties were analyzed by size-exclusion chromatography (Figure 1B) and ${ }^{1} \mathrm{H}$ NMR (Supporting Information File 1, Figure S1).

According to anionic polymerization theory, the amount of 1,4-isoprene units in PIPEOs was larger than $88 \%$ due to the polymerization in toluene and the polydispersity indices (PDI) being relatively low (Table 1). Only PIPEO $_{877}$ showed an increased polydispersity index, which was likely caused by the high amount of sec-butyllithium used as initiator to obtain the low molecular weight of the polymer.

The polydispersity indices of the PIPEO block copolymers were slightly larger than those of the PI precursors, probably because of side reactions during the polymerization of ethylene oxide utilizing the monomer-activated approach [52]. However, an incomplete initiation of the second block could be excluded as side reaction since no tailing within the size exclusion chromatography traces has been observed. Thus, effects on the selfassembly behavior of the block copolymers in aqueous solutions were not expected.

\section{PIPEO block copolymer-phospholipid membranes}

As mixtures of PIPEO and DPhPC have not been analyzed before, the ability of this type of lipopolymer mixture to form 
A<smiles>C=CC(C)=C[C@@H](C)C(C)CC</smiles>

B
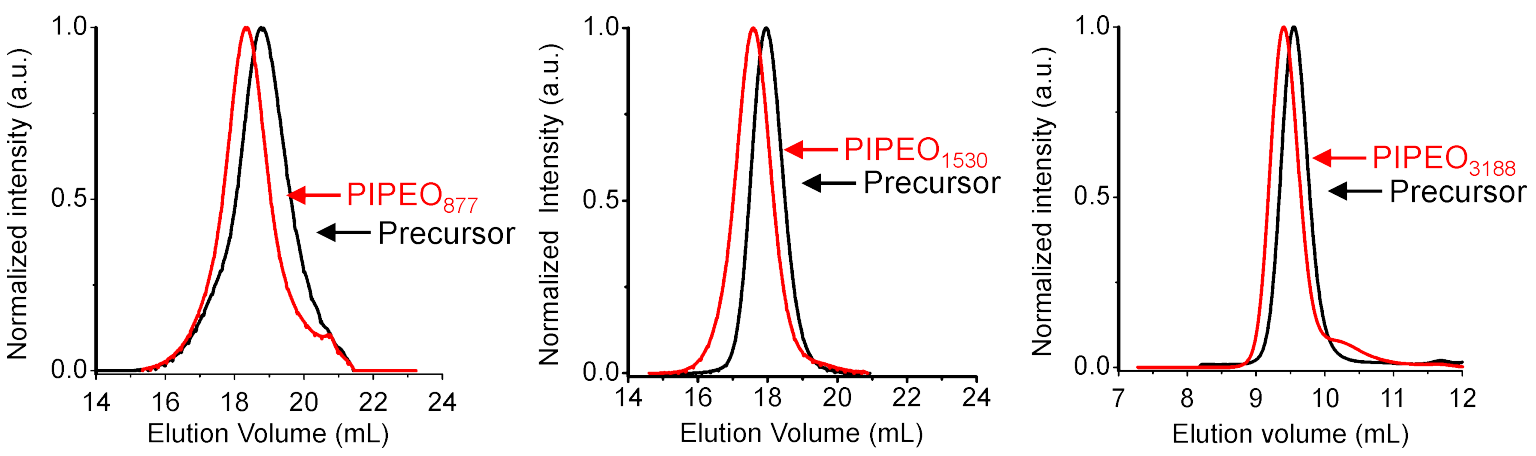

Figure 1: Synthesis of PIPEO block copolymers. (A) Reaction scheme for the synthesis of poly(1,4-isoprene-block-ethylene oxide) block copolymers Anionic polymerization of isoprene in toluene was initiated with sec-butyl lithium. Sequential polymerization of ethylene oxide was enabled by triisobutyl aluminium. (B) Size exclusion chromatography traces of synthesized PIPEO block copolymers and corresponding poly(isoprene) precursors. The shifts towards lower elution volumes of the block copolymers indicate higher molecular weights.

\begin{tabular}{|c|c|c|c|c|}
\hline block copolymer & molecular weight ${ }^{\mathrm{b}}(\mathrm{g} / \mathrm{mol})$ & fraction of $\mathrm{PI}^{\mathrm{b}}(\mathrm{w} / \mathrm{w})$ & polydispersity index of $\mathrm{PI}^{\mathrm{b}}$ & polydispersity index of PIPEOC \\
\hline $\mathrm{PIPEO}_{877}$ & 877 & 0.70 & 1.28 & 1.32 \\
\hline PIPEO $_{1530}$ & 1530 & 0.71 & 1.09 & 1.16 \\
\hline $\mathrm{PIPEO}_{3188}$ & 3188 & 0.64 & 1.07 & 1.11 \\
\hline
\end{tabular}

aPI: poly(1,4-isoprene) block; PIPEO: poly(1,4 isoprene-block-ethylene oxide) block copolymer; ${ }^{b}$ determined by ${ }^{1} \mathrm{H}$ NMR spectroscopy; ${ }^{\mathrm{C}} \mathrm{determined}$ by size-exclusion chromatography.

membranes, as well as the appearance and the characteristics of these membranes were examined. To assess the miscibility of PIPEO and DPhPC, block copolymer-phospholipid vesicles (lipopolymersomes) were prepared by electroformation [53] in aqueous solutions. Confocal fluorescence microscopy of vesicles dyed with fluorescent lipid (TopFluorPC) and nile red showed that blends of 90 mol \% PIPEO block copolymers and $10 \mathrm{~mol} \% \mathrm{DPhPC}$ form giant vesicles (Figure 2A). Nile red was used as a general hydrophobic dye to visualize the membranes; TopFluorPC was used to assess possible phase separation between lipids and polymers. The molecular weight of PIPEO appeared to have no observable effect on the formation of vesicles despite the hydrophobic mismatch between lipid and polymer. This finding indicated that the selected PIPEO and DPhPC were highly miscible. The absence of phase separation towards micrometer-scale lipid- and polymer-rich domains was in line with other lipopolymer mixtures at a similar lipid-topolymer ratio $[39,42,45]$ and similar membrane curvature [3941,43-45,54,55]. Lipopolymer vesicles formed from mixtures containing more than $50 \mathrm{~mol} \% \mathrm{DPhPC}$, however, revealed a heterogeneous distribution of TopFluorPC and a clear phase separation between polymer and lipid (Supporting Information File 1, Figure S2). Pure DPhPC vesicles prepared under similar conditions were significantly smaller than those composed of PIPEO and DPhPC (Figure 2B). They revealed completely different morphologies than the lipopolymersomes. 
A
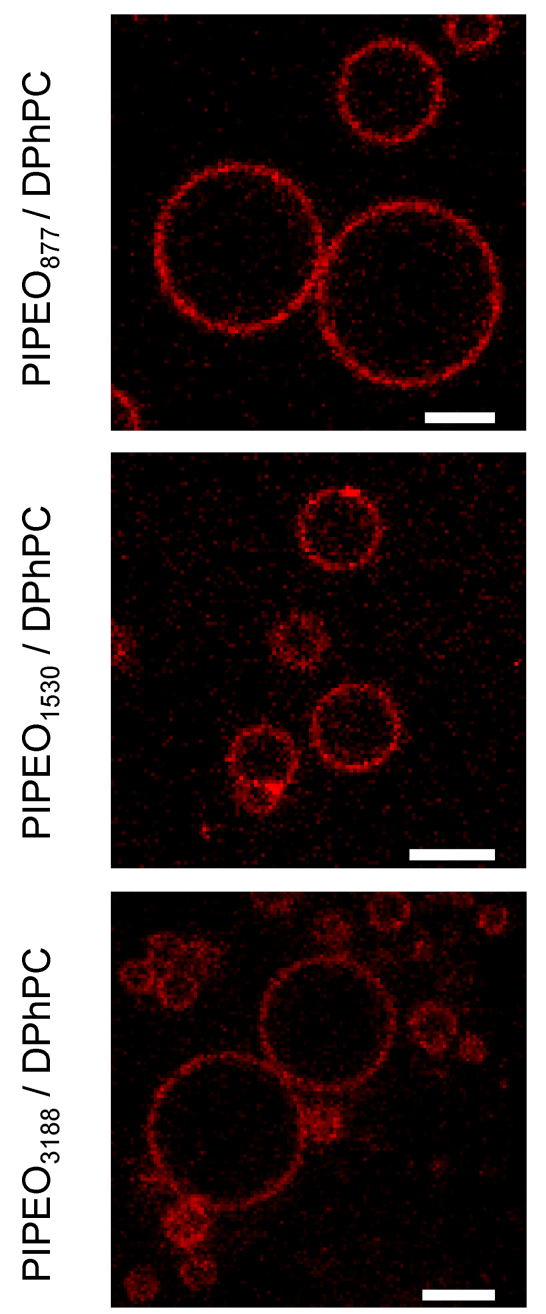

Nile Red
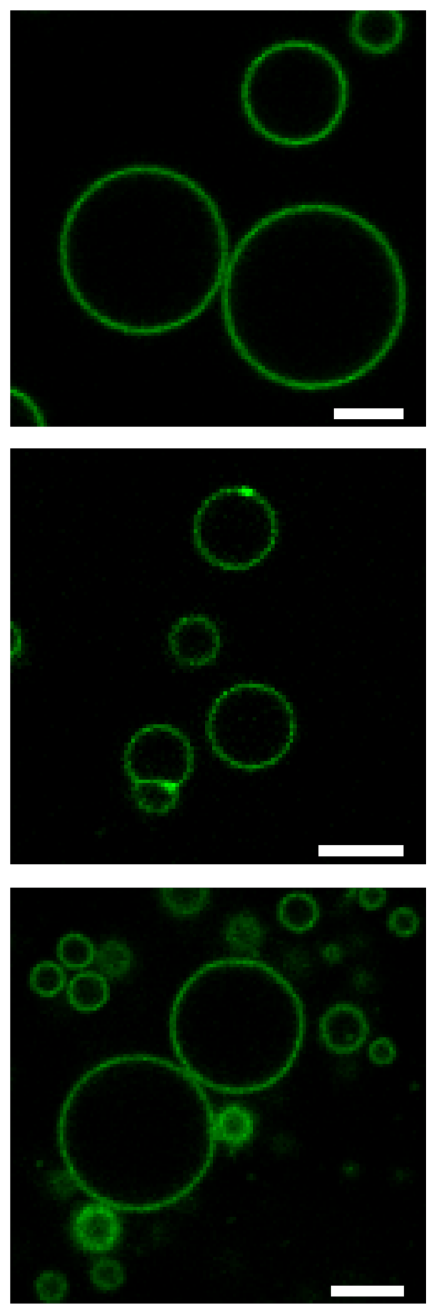

TopFluor PC
B
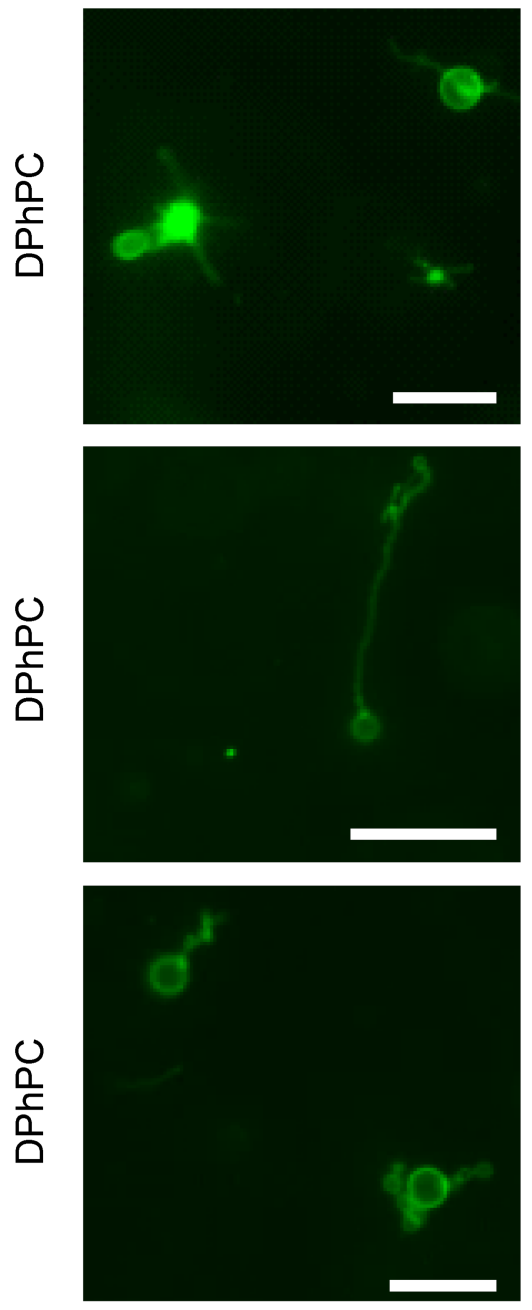

TopFluor PC

Figure 2: Confocal images of (A) giant unilamellar vesicles created by electroformation in saccharose solution from lipopolymer mixtures comprising $90 \mathrm{~mol} \%$ PIPEO block copolymers and $10 \mathrm{~mol} \%$ phospholipids and (B) vesicles obtained from pure DPhPC with the same electroformation parameters as for the lipopolymer mixtures shown in A. Vesicular membranes were fluorescently labeled with TopFluorPC and nile red. The scale bars correspond to $20 \mu \mathrm{m}$.

Using impedance spectroscopy, we attempted to gain insight into the electrical properties of planar PIPEO/DPhPC lipopolymer membranes. As reference, pure PIPEO (Supporting Information File 1, Figure S3) and DPhPC membranes were characterized as well. The spectra were interpreted in terms of an equivalent circuit consisting of an ohmic resistance in series with a resistance-capacitance (RC) pair in parallel, corresponding to an electrolyte-membrane-electrolyte interface $[16,56]$ (Table 2).

The membranes formed by $\mathrm{PIPEO}_{877} / \mathrm{DPhPC} \mathrm{PIPEO}_{1530} /$ DPhPC, PIPEO $_{877}$ and PIPEO $_{1530}$ revealed ohmic resistances above $1 \mathrm{G} \Omega$. $\mathrm{PIPEO}_{3188}$ yielded a resistance close to $1 \mathrm{G} \Omega$. In contrast, the mean resistance of membranes composed of $\mathrm{PIPEO}_{3188} / \mathrm{DPhPC}$ was significantly lower. Nevertheless, the resistances of all the lipopolymer membranes studied appeared to be sufficiently high to allow for monitoring single-channel currents across these membranes [57,58].

Based on the capacitance measurements and an estimated membrane area of roughly $5000 \mu \mathrm{m}^{2}$, the membrane thicknesses for $\mathrm{PIPEO}_{877} / \mathrm{DPhPC} \mathrm{PIPEO}_{1530} / \mathrm{DPhPC}$ and $\mathrm{PIPEO}_{3188} / \mathrm{DPhPC}$ were calculated to be $7.3 \mathrm{~nm}, 7.3 \mathrm{~nm}$ and $10.1 \mathrm{~nm}$, respectively. These values were similar to the thickness of pure PIPEO $_{3188}$ membranes in vitreous ice imaged by transmission electron cryo-microscopy (Figure 3). 
Table 2: Electrochemical properties of lipopolymer membranes and bilayers from pure amphiphiles.

\begin{tabular}{lll} 
membrane composition & membrane resistance $(\mathrm{G} \Omega)$ & membrane capacitance $^{\mathrm{a}}(\mathrm{pF})$ \\
\hline PIPEO $_{877} / \mathrm{DPhPC}$ & $1.1 \pm 0.2$ & $50.3 \pm 2.5$ \\
PIPEO $_{1530} / \mathrm{DPhPC}$ & $13.9 \pm 7.5$ & $50.4 \pm 0.8$ \\
PIPEO $_{3188} / \mathrm{DPhPC}$ & $0.2 \pm 0.1$ & $47.5 \pm 2.1$ \\
PIPEO $_{877}$ & $1.2 \pm 0.4$ & $41.8 \pm 8.9$ \\
PIPEO $_{1530}$ & $2.8 \pm 0.2$ & $49.9 \pm 0.8$ \\
PIPEO$_{3188}$ & $1.0 \pm 0.3$ & $43.5 \pm 5.0$ \\
DPhPC & $0.5 \pm 0.2$ & $47.2 \pm 4.0$ \\
\hline
\end{tabular}

aAll membrane resistance $R_{\mathrm{m}}$ and membrane capacitance $C_{\mathrm{m}}$ values represent an average of $N=10$ independent experiments. The measured membrane area was approx. $5000 \mu \mathrm{m}^{2}$.
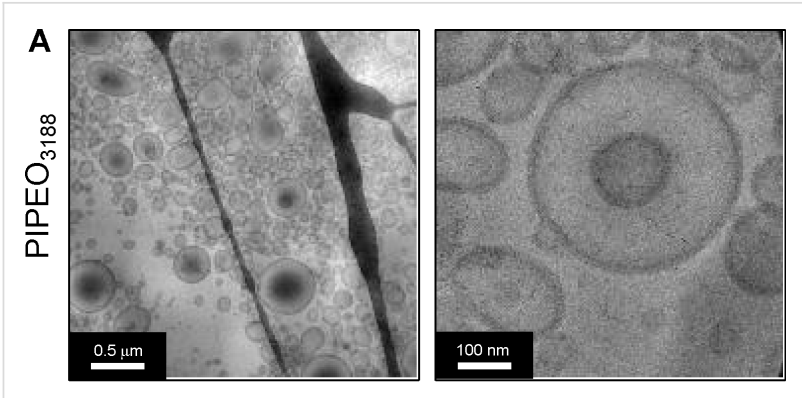

B

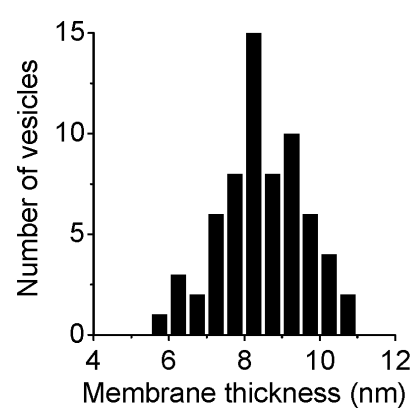

Figure 3: Thickness of pure PIPEO membranes determined by cryoelectron microscopy. (A) Micrographs of polymersomes formed by $\mathrm{PIPEO}_{3188}$ in vitreous ice. (B) Histogram of the membrane thickness of individual polymersomes made of $\mathrm{PIPEO}_{3188}$ based on the analysis of $N=65$ vesicles.

\section{Channel activity of OmpF in lipopolymer membranes}

Next, we studied the integration of OmpF (Figure 4) into planar PIPEO/DPhPC membranes of different thicknesses. With increasing molecular weight of PIPEO, the character of the formed assemblies was expected to change from more fluid and phospholipid-like to a thicker, stiffer polymeric behaviour $[18,59]$, similar to membranes composed of poly(2-methyl-2oxazoline-block-dimethylsiloxan-block-2-methyl-2-oxazoline) triblock copolymers [15,30,32].

Integration of OmpF into the membranes was monitored by measuring transmembrane ion currents (Figure 5A). Current

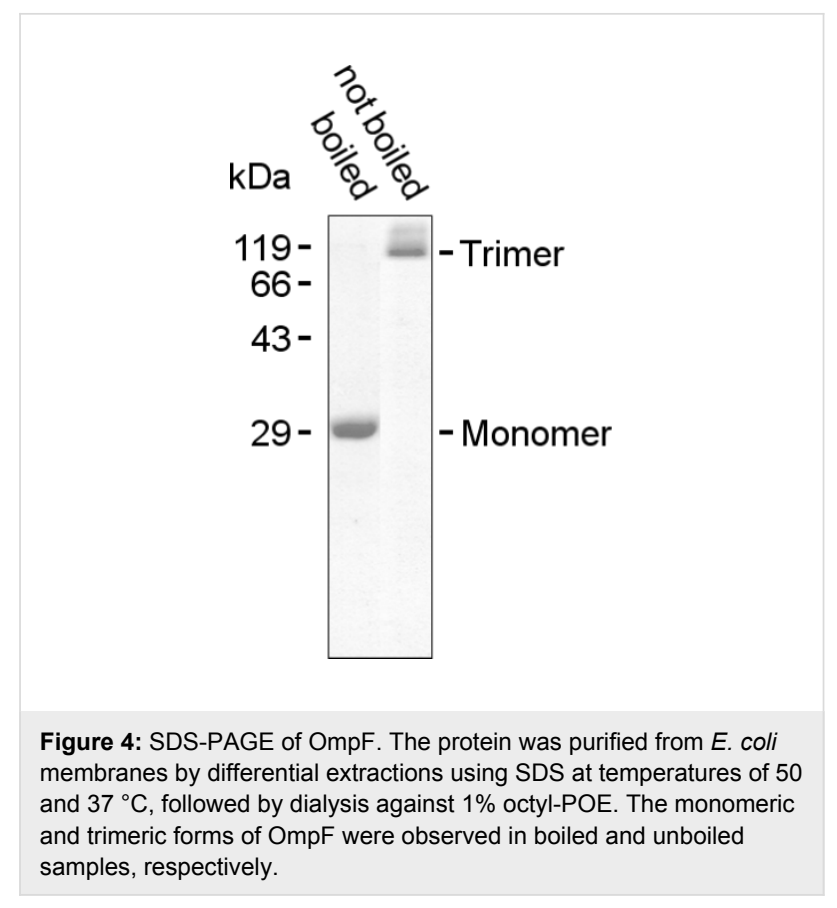

recordings taken at a low membrane potential of $50 \mathrm{mV}$ or $60 \mathrm{mV}$ showed characteristic steps of current increase reflecting the insertion of OmpF into all membranes, independent of the molecular weight of the PIPEO present. At higher voltages, in particular above $100 \mathrm{mV}$, gating in the transmembrane current was observed for all lipopolymer membranes (Figure 5B). This was attributed to reversible closing and opening of individual channels of OmpF [60-62]. A total of 31 insertion events revealed an average conductance level of OmpF in the membranes of about $2.1 \mathrm{nS}$ to $2.3 \mathrm{nS}$ at low membrane potentials, as also demonstrated in the histograms (Figure 5D). At high membrane potentials, single-channel conductance was about $0.7 \mathrm{nS}$ in $1 \mathrm{M} \mathrm{KCl}$ (Table 3), likely representing the conductance of a single pore of the OmpF trimer. These values were in line with conductance measurements of OmpF in pure DPhPC membranes in $1 \mathrm{M} \mathrm{KCl}$ (Figure 5C and Figure 5D) [60,62,63]. 
A

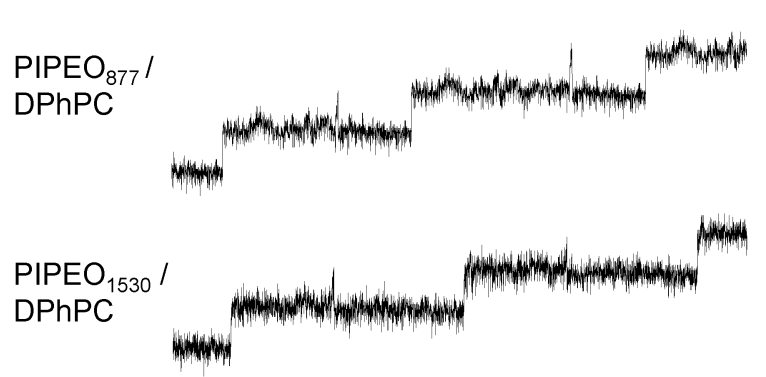

D

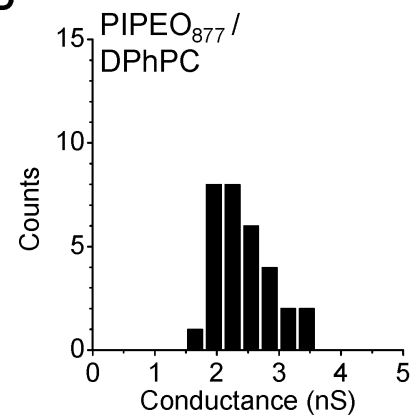

$\mathrm{PIPEO}_{3188} /$ DPhPC

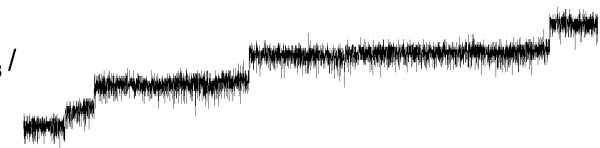

\section{B}

$\mathrm{PIPEO}_{877} /$

DPhPC
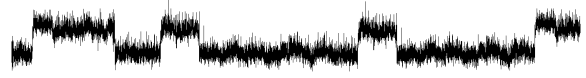

PIPEO $_{1530}$ /

DPhPC

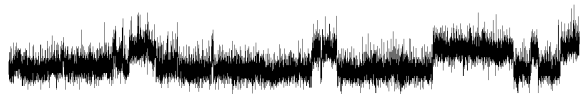

$\mathrm{PIPEO}_{3188} /$

DPhPC
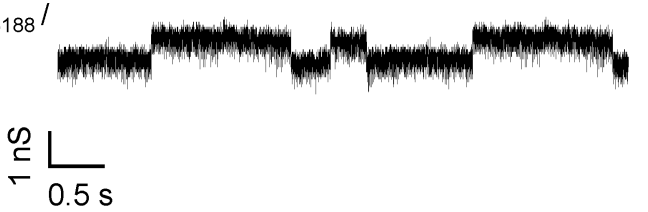

C

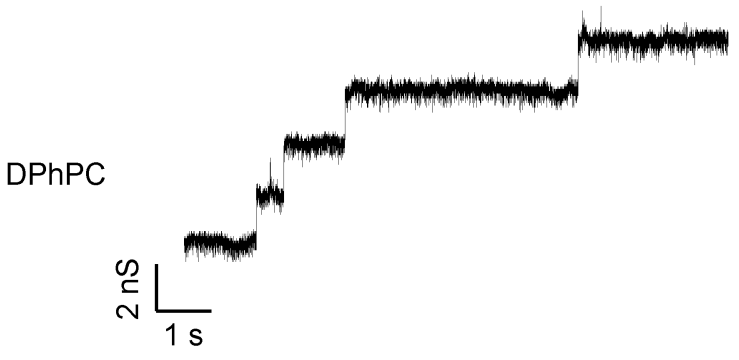

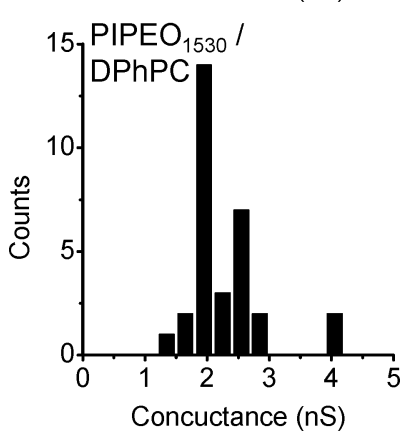

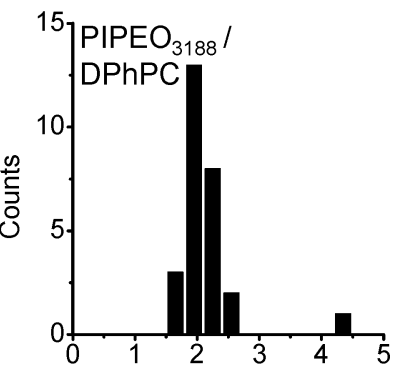

Conductance (nS)

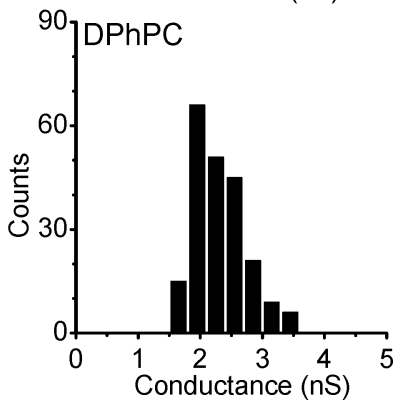

Figure 5: Channel activity of OmpF in planar lipopolymer membranes. Purified OmpF was added to both sides of the membrane formed of different PIPEO/DPhPC mixtures with polymer molar fraction of 0.9 . A solution of $1 \mathrm{M} \mathrm{KCl}$ was applied as electrolyte. (A) Insertion of OmpF into the membranes. A membrane potential of $\Delta V=+50 \mathrm{mV}$ (PIPEO $877 / 10 \mathrm{~mol} \% \mathrm{DPhPC}$ and PIPEO1530/10 mol \% DPhPC) and $\Delta V=+60 \mathrm{mV}(\mathrm{PIPEO} 3188 / 10$ $\mathrm{mol} \% \mathrm{DPhPC}$ ) was applied. (B) Current traces of individual channels of integrated OmpF in lipopolymer membranes at a membrane potential of $\Delta V=$ $+120 \mathrm{mV}$. (C) Current trace of OmpF channels integrating into a planar DPhPC membrane. The membrane voltage has been clamped to

$\Delta V=-50 \mathrm{mV}$. (D) Amplitude histograms (bin width $0.3 \mathrm{nS}$ ) of channel conductance values of OmpF. Recording of conductance increments were carried out as described in (A) and (C). The data represent the conductance valuess of $N=31$ (lipopolymer mixtures) and $N=213$ (pure DPhPC) measurements, respectively.

It should be noted that the probability of OmpF to insert into $\mathrm{PIPEO} / \mathrm{DPhPC}$ membranes was significantly lower than that of inserting into planar DPhPC bilayers. A possible explanation is the presence of minute amounts of chloroform in the PIPEO/ $\mathrm{DPhPC}$ membranes. Being well aware of the low compatibility of this solvent with proteins, this solvent led to the molecular dissolution of PIPEO. The presence of chloroform in our lipopolymer membranes may also be the reason why we did not observe typical three-step closing of trimeric OmpF channels at high voltages $(\Delta V>100 \mathrm{mV})$. 
Table 3: Single-channel conductance values of the OmpF pore in lipopolymer membranes.

\begin{tabular}{lll} 
membrane composition & membrane potential $(\mathrm{mV})$ & conductance in $1 \mathrm{M} \mathrm{KCl}(\mathrm{nS})$ \\
\hline PIPEO $_{877} / \mathrm{DPhPC}$ & 50 & $2.3 \pm 0.1$ \\
& 120 & $0.7 \pm 0.1$ \\
PIPEO $_{1530} / \mathrm{DPhPC}$ & 50 & $2.3 \pm 0.1$ \\
& 120 & $0.7 \pm 0,1$ \\
PIPEO $_{3188} / \mathrm{DPhPC}$ & $60^{\mathrm{b}}$ & $2.1 \pm 0.1$ \\
\end{tabular}

aMean \pm s.e.m, $N=31 ;{ }^{b}$ note that there was no insertion of $\mathrm{OmpF}$ into the membrane at a potential of $+50 \mathrm{mV}$.

Nevertheless, OmpF reconstituted in the lipopolymer membranes displayed typical voltage-dependent conductivities. This was in contrast to earlier studies on OmpF integrated into pure polymeric membranes composed of poly(2-methyl-2-oxazolineblock-dimethylsiloxan-block-2-methyl-2-oxazoline) triblock copolymer that showed no voltage-dependent closing and thus single-channel conductance for OmpF even at transmembrane voltages of $200 \mathrm{mV}$ [38].

To provide further evidence of OmpF insertion into lipopolymer membranes, we also followed the integration of OmpF by using impedance spectroscopy. Figure 6 exemplarily shows an impedance spectrum of a $\mathrm{PIPEO}_{1530} / \mathrm{DPhPC}$ membrane in buffer containing $1 \mathrm{M} \mathrm{KCl}$ in absence and presence of OmpF. In the absence of $\mathrm{OmpF}$, the $|Z(\Omega)|$ spectrum shows a frequency-independent plateau at low frequencies and a linear decrease with increasing frequencies. The monotonic decay of the impedance with frequency can be accounted for by the membrane capacitance, the plateau at low frequencies by the membrane resistance. This interpretation is supported by the detected phase shift that tended to be $0^{\circ}$ at high frequencies, accounting for an ohmic resistance, whereas the $90^{\circ}$ shift in parallel with the monotonic decay of impedance between $10 \mathrm{~Hz}$ and $10^{5} \mathrm{~Hz}$ accounted for a capacitive contribution. Upon integration of OmpF the spectrum changed. At the low-frequency end, lower levels of impedance were detected in parallel with a phase shift of $0^{\circ}$, indicating a reduced membrane resistance as expected for membranes perforated by protein pores [16]. At the high-frequency end of the spectrum, the shoulder in the impedance in parallel with the local minimum in the phase shift indicated a new ohmic element that also supports insertion of OmpF into the membrane [56].

According to the detected decrease in membrane resistance of approximately $100 \mathrm{M} \Omega$ and a trimeric conductance of OmpF of roughly $2 \mathrm{nS}$ [60], the number of functional OmpF pores present in the membrane was calculated to be five. This demonstrates the sensitivity of impedance spectroscopy towards

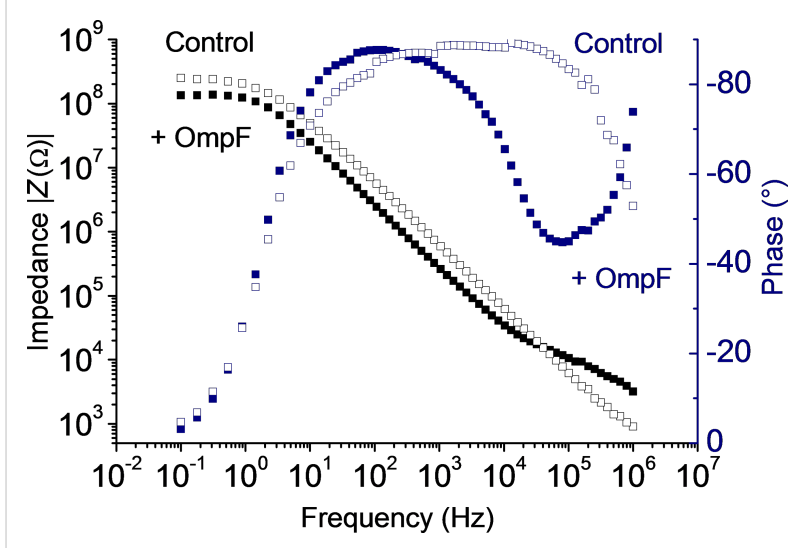

Figure 6: Bode representation of impedance and phase data of a planar $\mathrm{PIPEO}_{1530} / \mathrm{DPhPC}$ membrane in buffer containing $1 \mathrm{M} \mathrm{KCl}$ before and after incorporation of OmpF. The lowering of membrane resistance and the appearance of a second plateau-like feature at higher frequencies indicate the $O m p F$ present in the membrane. $|Z|$ in absence (empty squares) and presence (filled squares) of OmpF; phase in absence (empty circles) and presence (filled circles) of OmpF.

changes in the system to be analyzed [64]. Combined with the results for channel activity mentioned previously, the presence of functional $\mathrm{OmpF}$ in the lipopolymer membranes is strongly indicated, although no complete typical channel activity was observeable.

\section{Conclusion}

In the past years, lipopolymer membranes gained more and more interest, as the properties of such assemblies can be steadily varied between the characteristics of a lipid bilayer and that of synthetic polymer membranes. By simply mixing lipids and amphiphilic polymers, a plethora of possible chemical and mechanical characteristics of polymeric membranes can be combined with the inherent biofunctionality of lipid bilayers [39-45,54]. Thereby, lipopolymer membranes became attractive also for membrane protein reconstitution. To our knowledge, the function of reconstituted proteins, however, has not been assessed in these systems yet. 
Previous studies have shown that integration of membrane proteins into pure polymeric membranes depends more on the polymer flexibility than on the membrane thickness $[15,24,31,65]$. In this study, we selected amphiphilic PIPEO block copolymers and blended them with DPhPC to form lipopolymer membranes. Compared with other polymers used for the formation of biomimetic membranes [29,30,32], the hydrophobic PI blocks of PIPEO mimic the structure of unsaturated hydrophobic tails of lipids more closely, providing a more biomimetic character of the generated membranes. The obtained lipopolymer membranes exhibited a homogeneous distribution of its components and allowed for the reconstitution of OmpF as well as for a measurement of its channel activity. Until now, this could not be achieved for OmpF and has only rarely been assessed for other membrane proteins $[29,30,38]$.

The enhanced mechanical stability of synthetic polymer membranes may expand the field of possible applications towards new technical processes using membrane proteins.

\section{Experimental}

All chemicals used were of analytical grade and were obtained from Sigma Aldrich (Steinheim, Germany) unless stated otherwise. Isoprene was purchased from ABCR (Karlsruhe, Germany), ethylene oxide from Linde (Pullach, Germany).

\section{Polymer synthesis}

Typical techniques for anionic polymerizations including highvacuum techniques were used to synthesize the block copolymers as described for example in the review of Hadjichristidis et al. [66]. Solvent and monomers were purified prior to use. Toluene was stirred over $\mathrm{Na}-\mathrm{K}$ alloy and benzophenone. Isoprene and ethylene oxide were purified in a two-step procedure: First, the monomers were stirred over calcium hydride for $1 \mathrm{~h}$ at $-70{ }^{\circ} \mathrm{C}$ (dry ice-ethanol mixture), then transferred to a second flask and stirred for $1 \mathrm{~h}$ over di- $n$-butylmagnesium under the same conditions. To transfer the solvent and the monomers from one flask to another, cryo-distillation under static vacuum conditions was used.
The typical procedure for polymerization of the block copolymers is briefly mentioned here. To a volume of $100 \mathrm{~mL}$ of purified toluene in a 2-neck $250 \mathrm{~mL}$ reaction flask connected to the vacuum line, the desired volume (see Table 4) of purified isoprene was added at $-140{ }^{\circ} \mathrm{C}$. Just at the melting point of the isoprene solution, sec-butyllithium was added under an $\mathrm{Ar}$ atmosphere via syringe at $5{ }^{\circ} \mathrm{C}$ through a rubber septum in the quantity needed. Polymerization was carried out at $35{ }^{\circ} \mathrm{C}$ overnight. After polymerization of the isoprene block, a small sample of the precursor reaction mixture was collected via a syringe under an Ar atmosphere for analysis. The precursor was precipitated in cold ethanol as oil, decanted and dried in vacuum for further analysis.

The sequential polymerization of ethylene oxide is a modification of the method published by Reijsek et al. [52]. Triisobutylaluminium was added to the reaction mixture at room temperature at the double stoichiometry of the active polyisoprenyl chains. After $3 \mathrm{~h}$, the desired volume of purified ethylene oxide at $-110{ }^{\circ} \mathrm{C}$ is distilled to the reaction mixture and polymerization of the second block is carried out at room temperature over night. Active chains are deactivated by adding a degassed 1:1 mixture of acetic acid and methanol via a syringe. After polymerization, the block copolymer is isolated by precipitation in cold ethanol, decanted, then re-dissolved in chloroform, filtrated and dried in vacuum. PIPEOs are stored at $-20{ }^{\circ} \mathrm{C}$ under an $\mathrm{Ar}$ atmosphere.

\section{Polymer analysis Size-exclusion chromatography}

SEC was performed on a SECcurity System (PSS GmbH, Mainz, Germany) at $40^{\circ} \mathrm{C}$. Sample signals were detected with Agilent RI and UV-DAD detectors. THF was used as solvent

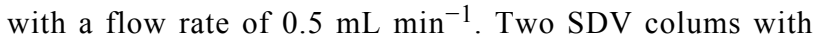
$1000 \AA$ pore size were used. Calibration of the system was done with poly(styrene) standards (ReadyCal, PSS GmbH, Mainz, Germany). Samples were evaluated with the PSS WinGPC Unichrom software, version 8.10. For analysis, approx. $5 \mathrm{mg}$ of the polymer sample were dissolved in THF at a concentration between $2 \mathrm{mg} \mathrm{mL}^{-1}$ and $4 \mathrm{mg} \mathrm{mL}^{-1}$. A volume of $1 \mu \mathrm{L}$ of

Table 4: Used amounts of isoprene, ethylene oxide, sec-butyllithium and triisobutylaluminium for block copolymer synthesis.

\begin{tabular}{lllll} 
block copolymer & isoprene $(\mathrm{mL})$ & ethylene oxide $(\mathrm{mL})$ & sec-butyllithium ${ }^{\text {a }}(\mathrm{mL})$ & triisobutylaluminium $(\mathrm{mL})$ \\
\hline PIPEO $_{877}$ & 5 & 1.8 & 2.76 & 1.63 \\
PIPEO $_{1530}$ & 5 & 1.7 & 2.30 & 1.64 \\
PIPEO $_{3188}$ & 10 & 3.5 & 1.74 & 1.30 \\
\hline
\end{tabular}

asolution in cyclohexane $(c=1.4 \mathrm{M})$. 
o-dichlorobenzene was added to each sample as internal standard.

\section{Nuclear magnetic resonance spectroscopy}

Approx. $30 \mathrm{mg}$ of sample was dissolved in $0.6 \mathrm{~mL}$ deuterated chloroform (Deutero, Kastellaun, Germany) and measured at $500 \mathrm{MHz}$ with a Bruker Avance 500 spectrometer. The solvent residual peak in the spectrum was used as a reference for chemical shifts. The spectra were evaluated using the MestReNova Software.

\section{Cryo transmission electron microscopy}

To examine the morphology and membrane thickness of polymer vesicles by transmission electron microscopy (TEM), a drop of the vesicle solution of interest was placed on copper grids with lacey carbon film (200 mesh, Plano, Wetzlar, Germany), blotted with filter paper, vitrified in liquid ethane (Zeiss Cryobox, Zeiss NTS GmbH, Germany) and stored in liquid nitrogen until inserted under nitrogen atmosphere within a cryo transfer holder (CT3500, Gatan, USA) to the TEM column. Specimens were observed at a temperature of approx. $-180{ }^{\circ} \mathrm{C}$ using a LEO922 OMEGA EFTEM (Zeiss, Oberkochen, Germany) operated at $200 \mathrm{kV}$.

\section{Block copolymer-phospholipid mixtures}

Mixtures of block copolymers and phospholipids (molar ratio 9:1) were prepared by combining $200 \mu \mathrm{L}$ of block copolymer solutions (10 mg mL $\mathrm{mL}^{-1}$ in THF) with solutions $\left(2 \mathrm{mg} \mathrm{mL}^{-1}\right.$ in chloroform) of a mixture (97.5:2.5 molar ratio) of 1,2-diphytanoyl-sn-glycero-3-phosphocholine (DPhPC) and 1-palmitoyl2-(dipyrrometheneboron difluoride)undecanoyl-sn-glycero-3phosphocholine (TopFluorPC, both Avanti Polar Lipids, Alabaster, USA). The block copolymer solutions of PIPEO $_{877}$, PIPEO $_{1530}$ and PIPEO $_{3188}$ were mixed with 107.42, 61.57 and $29.55 \mu \mathrm{L}$ of the phospholipid solution, respectively. From these mixtures, giant unilamellar vesicles (GUV) were formed using the electroformation technique [53]. For mixtures comprising of $\mathrm{PIPEO}_{877}$ and $\mathrm{PIPEO}_{3188}$, an alternating voltage of $3 \mathrm{~V}$ at $70 \mathrm{~Hz}$ was applied with the Vesicle Prep Pro (Nanion, Munich, Germany). Mixtures based on PIPEO $_{1530}$ were subjected to an alternating voltage of $10 \mathrm{~V}$ at $300 \mathrm{~Hz}$. As electrolyte, a saccharose solution $(260 \mathrm{mM})$ was used.

To observe the mixing behavior of the lipopolymer mixtures, one day after vesicle formation, the GUV were observed with confocal fluorescence microscopy using a Zeiss LSM710 (Carl Zeiss, Oberkochen, Germany) at excitation wavelengths of 488 and $561 \mathrm{~nm}$. Respectively, the emission of the TopFluorPC lipid was detected between 493 and $543 \mathrm{~nm}$, and nile red emission in the range of 594 to $753 \mathrm{~nm}$ using a plan apo $63 \times$ oil immersion objective.

\section{Isolation of OmpF}

Native OmpF protein was purified from Escherichia coli strain $\mathrm{B}^{\mathrm{E}}$ BL21(DE3)omp6 [9], lacking both LamB and OmpC [6,10]. Briefly, cells from a one liter culture were resuspended in $50 \mathrm{mM}$ Tris- $\mathrm{HCl}$ buffer ( $\mathrm{pH}$ 7.5) containing $2 \mathrm{mM} \mathrm{MgCl}_{2}$ and DNAse and broken by passing through a French press. Unbroken cells were removed by a low-speed centrifugation, then, the supernatant was centrifuged at $100000 \mathrm{~g}$ for $1 \mathrm{~h}$. The pellet was resuspended in $50 \mathrm{mM}$ Tris- $\mathrm{HCl}(\mathrm{pH} 7.5)$ and mixed with an equal volume of SDS buffer containing $4 \%(\mathrm{w} / \mathrm{v})$ sodium dodecyl sulfate (SDS), $2 \mathrm{mM} \beta$-mercaptoethanol and $50 \mathrm{mM}$ Tris- $\mathrm{HCl}(\mathrm{pH} 7.5)$. After $30 \mathrm{~min}$ incubation at a temperature of $50^{\circ} \mathrm{C}$, the solution was centrifuged at $100000 \mathrm{~g}$ for $1 \mathrm{~h}$. The pellet was resuspended in SDS-salt buffer containing $2 \%$ SDS, $0.5 \mathrm{M} \mathrm{NaCl}, 50 \mathrm{mM}$ Tris- $\mathrm{HCl}(\mathrm{pH} 7.5)$, incubated at a temperature of $37{ }^{\circ} \mathrm{C}$ for $30 \mathrm{~min}$ and centrifuged again at $100000 \mathrm{~g}$ for $30 \mathrm{~min}$. The supernatant containing OmpF was dialysed overnight against $20 \mathrm{mM}$ Tris (pH 8), $1 \mathrm{mM}$ EDTA and $1 \%(\mathrm{w} / \mathrm{v}) n$-octyl polyoxyethylene (octyl-POE). The purity of the protein was assessed by SDS-PAGE.

\section{Formation of planar lipopolymer membranes}

Planar membranes of the lipopolymer mixtures were prepared across a circular aperture with a diameter of $400 \mu \mathrm{m}$ in the partitioning wall of a custom-built black lipid bilayer Teflon chamber. The volume of each compartment, separated by the partionining wall, was $5 \mathrm{~mL}$ [67]. PIPEO/DPhPC in chloroform $(10 \mu \mathrm{L})$ was applied around the aperture of the chamber and allowed to dry to get rid of organic solvent. Then, the chambers on both sides of the aperture were filled with degassed $\mathrm{KCl}$ saline $(1 \mathrm{M} \mathrm{KCl}, 20 \mathrm{mM}$ Tris $(\mathrm{pH} 8))$ and $2 \mu \mathrm{L}$ of $\mathrm{PIPEO} / \mathrm{DPhPC}$ in chloroform was painted across the aperture with a fine brush. Successful self-assembly of a membrane was monitored by capacitance measurements.

\section{Electrochemical impedance spectroscopy}

Electrochemical impedance spectroscopy of PIPEO, PIPEO/ $\mathrm{DPhPC}$ and DPhPC membranes was performed using a Zahner IM6 electrochemical workstation equipped with HighZ-Probes (Zahner-Elektrik, Kronach, Germany), respectively. The HighZ-Probes were connected to $\mathrm{Ag} / \mathrm{AgCl}$ electrodes immersed into the electrolyte compartments on both sides of the formed membranes. Measurements were performed in the range between $1 \mathrm{MHz}$ and $100 \mathrm{mHz}$ at an offset of $0 \mathrm{mV}$ and an amplitude of $10 \mathrm{mV}$. Data acquisition was performed with the Thales Z-Man 1.18 software package from Zahner-Elektrik. The set-up was covered by a custom-built Faraday cage.

\section{Single- and multi-channel measurements}

Current fluctuations through single and multiple OmpF channels reconstituted into planar PIPEO/DPhPC and DPhPC bilay- 
ers were recorded following standard protocols [9,68,69]. After formation of the bilayers we made sure, that the current trace reflects a stable baseline. Then $\mathrm{OmpF}$ was added by pipetting 10 to $50 \mu \mathrm{L}$ of purified protein $\left(1 \mathrm{mg} \mathrm{mL}^{-1}\right.$ to $2 \mathrm{mg} \mathrm{mL}^{-1}$ in $20 \mathrm{mM}$ Tris (pH 8 ), $1 \mathrm{mM}$ EDTA and $1 \% \mathrm{w} / \mathrm{v}$ octyl-POE) to both sides of the membrane. At this dilution, the concentration of octyl-POE $(0.01 \% \mathrm{w} / \mathrm{v})$ is below its $\mathrm{cmc}$ value and a channellike structure, formed by the surfactant is very unlikely. Current fluctuations through single and multiple channels were recorded in voltage-clamp mode using an Axon Axopatch 200B amplifier (Molecular Devices, Sunnyvale, USA) with a capacitive headstage (Axon CV203 BU) connected to the bilayer chambers by a pair of custom-made $\mathrm{Ag} / \mathrm{AgCl}$ electrodes. Current signals were filtered at $2 \mathrm{kHz}$ and digitally sampled at $10 \mathrm{kHz}$ with an Axon Digidata 1322A digitizer controlled by the Clampex 10.2 software (Molecular Devices, Sunnyvale, USA).

\section{Supporting Information}

\section{Supporting Information File 1}

Additional experimental data.

[http://www.beilstein-journals.org/bjnano/content/ supplementary/2190-4286-7-80-S1.pdf]

\section{Acknowledgements}

M.B. likes to thank the Fund of the German Chemical Industry for the Kekulé Fellowship and the Elite Network of Bavaria for intellectual support. The electrophysiology study was partly supported by a Competence Network on Functional Nanostructures grant of the Baden-Württemberg Stiftung (TP-A03) to S.N.

\section{References}

1. Branton, D.; Deamer, D. W.; Marziali, A.; Bayley, H.; Benner, S. A.; Butler, T.; Di Ventra, M.; Garaj, S.; Hibbs, A.; Huang, X.; Jovanovich, S. B.; Krstic, P. S.; Lindsay, S.; Ling, X. S.; Mastrangelo, C. H.; Meller, A.; Oliver, J. S.; Pershin, Y. V.; Ramsey, J. M.; Riehn, R.; Soni, G. V.; Tabard-Cossa, V.; Wanunu, M.; Wiggin, M.; Schloss, J. A. Nat. Biotechnol. 2008, 26, 1146. doi:10.1038/nbt.1495

2. Derrington, I. M.; Butler, T. Z.; Collins, M. D.; Manrao, E.; Pavlenok, M.; Niederweis, M.; Gundlach, J. H. Proc. Natl. Acad. Sci. U. S. A. 2010, 107, 16060. doi:10.1073/pnas.1001831107

3. Loman, N. J.; Quick, J.; Simpson, J. T. Nat. Methods 2015, 12, 733. doi:10.1038/nmeth.3444

4. Loman, N. J.; Watson, M. Nat. Methods 2015, 12, 303. doi:10.1038/nmeth.3327
5. Ip, C. L. C.; Loose, M.; Tyson, J. R.; de Cesare, M.; Brown, B. L.; Jain, M.; Leggett, R. M.; Eccles, D. A.; Zalunin, V.; Urban, J. M.; Piazza, P.; Bowden, R. J.; Paten, B.; Mwaigwisya, S.; Batty, E. M.; Simpson, J. T.; Snutch, T. P.; Birney, E.; Buck, D.; Goodwin, S.; Jansen, H. J.; O'Grady, J.; Olsen, H. E. F1000Research 2015, 4, 1075. doi:10.12688/f1000research.7201.1

6. Kusters, I.; van den Bogaart, G.; Kedrov, A.; Krasnikov, V.; Fulyani, F.; Poolman, B.; Driessen, A. J. Structure 2011, 19, 430. doi:10.1016/j.str.2010.12.016

7. Mahendran, K. R.; Lamichhane, U.; Romero-Ruiz, M.; Nussberger, S.; Winterhalter, M. J. Phys. Chem. Lett. 2013, 4, 78. doi:10.1021/jz301790h

8. Mahendran, K. R.; Romero-Ruiz, M.; Schlösinger, A.; Winterhalter, M.; Nussberger, S. Biophys. J. 2012, 102, 39. doi:10.1016/j.bpj.2011.11.4003

9. Romero-Ruiz, M.; Mahendran, K. R.; Eckert, R.; Winterhalter, M.; Nussberger, S. Biophys. J. 2010, 99, 774. doi:10.1016/j.bpj.2010.05.010

10. Kowalczyk, S. W.; Kapinos, L.; Blosser, T. R.; Magalhães, T.; van Nies, P.; Lim, R. Y.; Dekker, C. Nat. Nanotechnol. 2011, 6, 433. doi:10.1038/nnano.2011.88

11. Wang, H.; Chung, T.-S.; Tong, Y. W.; Jeyaseelan, K.; Armugam, A.; Chen, Z.; Hong, M.; Meier, W. Small 2012, 8, 1185. doi:10.1002/smll.201102120

12. Zhao, Y.; Qiu, C.; Li, X.; Vararattanavech, A.; Shen, W.; Torres, J.; Hélix-Nielsen, C.; Wang, R.; Hu, X.; Fane, A. G.; Tang, C. Y. J. Membr. Sci. 2012, 423-424, 422. doi:10.1016/j.memsci.2012.08.039

13. Zhong, P. S.; Chung, T.-S.; Jeyaseelan, K.; Armugam, A. J. Membr. Sci. 2012, 407-408, 27. doi:10.1016/j.memsci.2012.03.033

14. Langowska, K.; Palivan, C. G.; Meier, W. Chem. Commun. 2013, 49, 128. doi:10.1039/c2cc36345c

15. Palivan, C. G.; Goers, R.; Najer, A.; Zhang, X.; Car, A.; Meier, W. Chem. Soc. Rev. 2015, 45, 377. doi:10.1039/c5cs00569h

16. Schmitt, E. K.; Steinem, C. Electrochemical Analysis of Ion Channels and Transporters in Pore-Suspending Membranes. In Applications of Electrochemistry and Nanotechnology in Biology and Medicine II; Eliaz, N., Ed.; Springer, 2012; Vol. 53, pp 267-333. doi:10.1007/978-1-4614-2137-5_5

17. Yuan, H.; Leitmannova-Ottova, A.; Tien, H. T. Mater. Sci. Eng., C 1996, 4, 35. doi:10.1016/0928-4931(95)00127-1

18. Discher, B. M.; Won, Y.-Y.; Ege, D. S.; Lee, J. C.-M.; Bates, F. S.; Discher, D. E.; Hammer, D. A. Science 1999, 284, 1143. doi:10.1126/science.284.5417.1143

19. Förster, S.; Plantenberg, T. Angew. Chem., Int. Ed. 2002, 41, 688. doi:10.1002/1521-3773(20020301)41:5<688::AID-ANIE688>3.0.CO;23

20. Antonietti, M.; Förster, S. Adv. Mater. 2003, 15, 1323. doi:10.1002/adma.200300010

21. Ahmed, F.; Photos, P. J.; Discher, D. E. Drug Dev. Res. 2006, 67, 4. doi:10.1002/ddr.20062

22. Dimova, R.; Seifert, U.; Pouligny, B.; Förster, S.; Döbereiner, H.-G. Eur. Phys. J. E 2002, 7, 241. doi:10.1140/epje/i200101032

23. Itel, F.; Chami, M.; Najer, A.; Lörcher, S.; Wu, D.; Dinu, I. A.; Meier, W. Macromolecules 2014, 47, 7588. doi:10.1021/ma5015403

24. Mecke, A.; Dittrich, C.; Meier, W. Soft Matter 2006, 2, 751. doi:10.1039/b605165k

25. Lin, J. J.; Bates, F. S.; Hammer, D. A.; Silas, J. A. Phys. Rev. Lett. 2005, 95, 026101. doi:10.1103/PhysRevLett.95.026101

26. Lin, J. J.; Ghoroghchian, P. P.; Zhang, Y.; Hammer, D. A. Langmuir 2006, 22, 3975. doi:10.1021/la052445c 
27. Lin, J. J.; Silas, J. A.; Bermudez, H.; Milam, V. T.; Bates, F. S.; Hammer, D. A. Langmuir 2004, 20, 5493. doi:10.1021/la036417a

28. Domes, S.; Filiz, V.; Nitsche, J.; Frömsdorf, A.; Förster, S. Langmuir 2010, 26, 6927. doi:10.1021/la904175u

29. Shen, Y.-x.; Saboe, P. O.; Sines, I. T.; Erbakan, M.; Kumar, M. J. Membr. Sci. 2014, 454, 359. doi:10.1016/j.memsci.2013.12.019

30. Zhang, X.; Tanner, P.; Graff, A.; Palivan, C. G.; Meier, W. J. Polym. Sci., Part A: Polym. Chem. 2012, 50, 2293. doi:10.1002/pola.26000

31. Pata, V.; Dan, N. Biophys. J. 2003, 85, 2111. doi:10.1016/S0006-3495(03)74639-6

32. Malinova, V.; Belegrinou, S.; de Bruyn Ouboter, D.; Meier, W. P. Adv. Polym. Sci. 2010, 223, 213. doi:10.1007/12_2009_10

33. Lee, A. G. Biochim. Biophys. Acta, Biomembr. 2004, 1666, 62. doi:10.1016/j.bbamem.2004.05.012

34. Phillips, R.; Ursell, T.; Wiggins, P.; Sens, P. Nature 2009, 459, 379. doi:10.1038/nature08147

35. Laganowsky, A.; Reading, E.; Allison, T. M.; Ulmschneider, M. B.; Degiacomi, M. T.; Baldwin, A. J.; Robinson, C. V. Nature 2014, 510, 172. doi:10.1038/nature13419

36. Chen, F.-Y.; Lee, M.-T.; Huang, H. W. Biophys. J. 2002, 82, 908. doi:10.1016/S0006-3495(02)75452-0

37. Keller, S. L.; Bezrukov, S. M.; Gruner, S. M.; Tate, M. W.; Vodyanoy, I.; Parsegian, V. A. Biophys. J. 1993, 65, 23. doi:10.1016/S0006-3495(93)81040-3

38. Meier, W.; Nardin, C.; Winterhalter, M. Angew. Chem., Int. Ed. 2000, 39, 4599 doi:10.1002/1521-3773(20001215)39:24<4599::AID-ANIE4599>3.0.CO ;2-Y

39. Le Meins, J.-F.; Schatz, C.; Lecommandoux, S.; Sandre, O. Mater. Today 2013, 16, 397. doi:10.1016/j.mattod.2013.09.002

40. Le Meins, J.-F.; Sandre, O.; Lecommandoux, S. Eur. Phys. J. E 2011, 34, 14. doi:10.1140/epje/i2011-11014-y

41. Chemin, M.; Brun, P.-M.; Lecommandoux, S.; Sandre, O.; Le Meins, J.-F. Soft Matter 2012, 8, 2867. doi:10.1039/C2SM07188F

42. Nam, J.; Beales, P. A.; Vanderlick, T. K. Langmuir 2011, 27, 1. doi:10.1021/la103428g

43. Schulz, M.; Glatte, D.; Meister, A.; Scholtysek, P.; Kerth, A.; Blume, A.; Bacia, K.; Binder, W. H. Soft Matter 2011, 7, 8100 doi:10.1039/C1SM05725A

44. Schulz, M.; Olubummo, A.; Bacia, K.; Binder, W. H. Soft Matter 2014, 10, 831. doi:10.1039/C3SM52040D

45. Nam, J.; Vanderlick, T. K.; Beales, P. A. Soft Matter 2012, 8, 7982. doi:10.1039/C2SM25646K

46. Kowal, J.; Wu, D.; Mikhalevich, V.; Palivan, C. G.; Meier, W. Langmuir 2015, 31, 4868. doi:10.1021/acs.langmuir.5b00388

47. Thoma, J.; Belegrinou, S.; Rossbach, P.; Grzelakowski, M.; Kita-Tokarczyk, K.; Meier, W. Chem. Commun. 2012, 48, 8811. doi:10.1039/C2CC32851H

48. Watanabe, Y. J. Protein Chem. 2002, 21, 169. doi:10.1023/A:1015372600277

49. Watanabe, Y. J. Chromatogr. A 2002, 961, 137. doi:10.1016/S0021-9673(02)00540-X

50. Phale, P. S.; Philippsen, A.; Kiefhaber, T.; Koebnik, R.; Phale, V. P.; Schirmer, T.; Rosenbusch, J. P. Biochemistry 1998, 37, 15663. doi:10.1021/bi981215c

51. Discher, D. E.; Eisenberg, A. Science 2002, 297, 967. doi:10.1126/science.1074972

52. Rejsek, V.; Desbois, P.; Deffieux, A.; Carlotti, S. Polymer 2010, 51, 5674. doi:10.1016/j.polymer.2010.09.061
53. Angelova, M. I.; Soléau, S.; Méléard, P.; Faucon, F.; Bothorel, P. Preparation of giant vesicles by external AC electric fields. Kinetics and applications. In Trends in Colloid and Interface Science VI; Helm, C.; Lösche, M.; Möhwald, H., Eds.; Dr. Dietrich Steinkopff Verlag, 1992; Vol. 89, pp 127-131. doi:10.1007/BFb0116295

54.Dao, T. P. T.; Fernandes, F.; Er-Rafik, M.; Salva, R.; Schmutz, M.; Brûlet, A.; Prieto, M.; Sandre, O.; Le Meins, J.-F. ACS Macro Lett. 2015, 4, 182. doi:10.1021/mz500748f

55. Schulz, M.; Werner, S.; Bacia, K.; Binder, W. H. Angew. Chem., Int. Ed. 2013, 52, 1829. doi:10.1002/anie.201204959

56. Guidelli, R.; Becucci, L. Electrochemistry of Biomimetic Membranes. In Applications of Electrochemistry and Nanotechnology in Biology and Medicine II; Eliaz, N., Ed.; Springer, 2012; Vol. 53, pp 147-266. doi:10.1007/978-1-4614-2137-5_4

57. Schmitt, E. K.; Weichbrodt, C.; Steinem, C. Soft Matter 2009, 5, 3347. doi:10.1039/B901683J

58. Steinem, C.; Janshoff, A.; Galla, H.-J.; Sieber, M. Bioelectrochem. Bioenerg. 1997, 42, 213. doi:10.1016/S0302-4598(96)05113-6

59. Aranda-Espinoza, H.; Bermudez, H.; Bates, F. S.; Discher, D. E. Phys. Rev. Lett. 2001, 87, 208301. doi:10.1103/PhysRevLett.87.208301

60. Benz, R. Crit. Rev. Biochem. 1985, 19, 145. doi:10.3109/10409238509082542

61. Danelon, C.; Suenaga, A.; Winterhalter, M.; Yamato, I. Biophys. Chem. 2003, 104, 591. doi:10.1016/S0301-4622(03)00062-0

62. Schmitt, E. K.; Vrouenraets, M.; Steinem, C. Biophys. J. 2006, 91 , 2163. doi:10.1529/biophysj.106.083592

63. Benz, R.; Janko, K.; Boos, W.; Läuger, P. Biochim. Biophys. Acta, Biomembr. 1978, 511, 305. doi:10.1016/0005-2736(78)90269-9

64. Barsoukov, E.; Macdonald, J. R., Eds. Impedance spectroscopy: theory, experiment, and applications, 2nd ed.; Wiley-Interscience: Hoboken, NJ, 2005. doi:10.1002/0471716243

65. Itel, F.; Najer, A.; Palivan, C. G.; Meier, W. Nano Lett. 2015, 15, 3871. doi:10.1021/acs.nanolett.5b00699

66. Hadjichristidis, N.; latrou, H.; Pispas, S.; Pitsikalis, M. J. Polym. Sci., Part A: Polym. Chem. 2000, 38, 3211. doi:10.1002/1099-0518(20000915)38:18<3211::AID-POLA10>3.0.CO; 2-L

67. Arnold, T.; Poynor, M.; Nussberger, S.; Lupas, A. N.; Linke, D. J. Mol. Biol. 2007, 366, 1174. doi:10.1016/j.jmb.2006.12.029

68. Mager, F.; Gessmann, D.; Nussberger, S.; Zeth, K. J. Membr. Biol. 2011, 242, 11. doi:10.1007/s00232-011-9372-8

69. Poynor, M.; Eckert, R.; Nussberger, S. Biophys. J. 2008, 95, 1511. doi:10.1529/biophysj.108.131003 


\section{License and Terms}

This is an Open Access article under the terms of the Creative Commons Attribution License

(http://creativecommons.org/licenses/by/2.0), which permits unrestricted use, distribution, and reproduction in any medium, provided the original work is properly cited.

The license is subject to the Beilstein Journal of Nanotechnology terms and conditions:

(http://www.beilstein-journals.org/bjnano)

The definitive version of this article is the electronic one which can be found at:

doi:10.3762/bjnano.7.80 